\title{
Symbolic analysis of analog circuits containing voltage mirrors and current mirrors
}

\author{
E. Tlelo-Cuautle $\cdot$ C. Sánchez-López • \\ E. Martínez-Romero • Sheldon X.-D. Tan
}

Received: 12 December 2009/Revised: 15 January 2010/Accepted: 16 January 2010/Published online: 4 February 2010

(C) The Author(s) 2010. This article is published with open access at Springerlink.com

\begin{abstract}
The pathological elements voltage mirror (VM) and current mirror (CM) have shown advantages in analog behavioral modeling and circuit synthesis, where many nullor-mirror equivalences have been explored to design and to transform voltage-mode circuits to current-mode ones and viceversa. However, both the VM and CM have not equivalents to perform automatic symbolic circuit analysis. In this manner, we introduce nullor-equivalents for these pathological elements allowing to include parasitics and to perform only symbolic nodal analysis. The nullor-equivalent of the CM is extended to provide multiple-outpus (MO-CM). Finally, two active filters containing VMs, CMs and MO-CMs are analysed to show the usefulness of the models.
\end{abstract}

Keywords Nullor · Voltage mirror · Current mirror . Symbolic analysis $\cdot$ Nodal analysis $\cdot$ Active filter

E. Tlelo-Cuautle was Visiting Researcher at University of California Riverside during 2009-2010 under a CONACyT sabbatical leave grant

E. Tlelo-Cuautle $(\bowtie) \cdot$ E. Martínez-Romero

INAOE, Tonantzintla, Mexico

e-mail: etlelo@inaoep.mx

C. Sánchez-López

UAT, Apizaco, Tlaxcala, Mexico

C. Sánchez-López

IMSE-CSIC, Sevilla, Spain

S. X.-D. Tan

University of California, Riverside, CA, USA

\section{Introduction}

The nullator and norator elements are quite useful in analog design automation (ADA). For instance, the ideal behavior of the voltage follower (VF) can be modeled using nullators, with the aim to synthesize different VF topologies. Further, the VF can be evolved to synthesize the voltage mirror (VM) [35]. The norator is useful to model the behavior of the current follower (CF), and it can be superimposed with the VF to design more complex devices, e.g. current conveyors [38].

The VF, VM, CF and the current mirror (CM) form the four unity-gain cells (UGCs) [34]. Among them, the CM could be the most useful cell covering a wide range of applications [9, 13, 31, 33, 43 ], and also it can provide multiple-outputs (MO-CM). The four UGCs can be combined to model the behavior of already known and new active devices [3]. For example, the inverting properties of the VM and CM leads us to design inverting and positivetype current conveyors [1, 25, 26, 27], which properties can improve the ones provided by the four terminal floating nullor (FTFN) [12].

In symbolic analysis of analog and VLSI circuits, several methods are described in [7, 17]. In particular, the nullator and the norator are quite useful to perform symbolic analysis by only applying nodal analysis (NA) [11, 22, 39]. Besides, the symbolic NA method requires that all active devices be modeled using nullors [14, 22, 39].

The modeling of active devices possessing inverting characteristics can be done by using the VM and $\mathrm{CM}$, as pathological elements [2, 20, 30, 42]. An important thing is that an analog circuit containing VMs and CMs also allows to transform circuit topologies or voltage-mode to currentmode circuits and vice-versa $[5,8,10,15,28,29,41]$. However, both the VM and CM can not be used in 
symbolic NA because their inverting characteristics imposse addition/subtraction limitations in the formulation process, i.e. there is not way to perform addition or deletion of columns or rows to preserve the inverting characteristics of either or both the VM and CM, as it is done in a nullor network [37]. In this manner, we are introducing nullorequivalents for the VM, CM and MO-CM to take advantage of the symbolic NA of nullor networks [7, 37, 39].

\section{Symbolic NA method}

As already shown in [22, 37, 39], the main advantage of transforming an analog circuit to a nullor network is to apply only NA in the formulation process, and to obtain a reduced system of equations for operational amplifier based circuits [7, 37], and in general for circuits containing non-NA compatible elements.

The first step of the NA-formulation consists to model all circuit elements, such as: active devices, controlled sources and independent voltage sources using nullors [5, 14, 39]. The modeling process must include grounded admittances as much as possible, because they have only one entry in the NA formulation [37], while floating ones may have up to four entries requiring more computational work. The symbolic NA formulation method $(i=Y v)$ can be summarized as follows:

1. Step 1: Describe the interconnection relationships of norators $P_{j}$, nullators $O_{j}$, and admittances by generating tables including names and nodes $(m, n)$.

2. Step 2: Calculate the indexes associated to set row and set column, and group grounded and floating admittances:

(a) ROW: Contains all nodes ordered by applying the norator property which nodes $(m, n)$ are virtually short-circuited. These indexes are used to fill vector $i$ and the admittance matrix $Y$.

(b) COL: Contains all nodes ordered by applying the nullator property which nodes $(m, n)$ are virtually short-circuited. These indexes are used to fill vector $v$ and the admittance matrix $Y$.

(c) Admittances: They are grouped into two tables: Table A includes all nodes (ordered), and in each node is the sum of all admittances connected to it. Table B includes all floating admittances and its nodes $(m, n)$.

3. Step 3: Use sets ROW and COL to fill vectors $i$ and $v$, respectively. To fill $Y$ : if in Table A a node is included in ROW and COL, introduce that admittance(s) in $Y$ at position (ROW index, COL index). For each admittance in Table B, search node $m$ in ROW and $n$ in COL (do the same but search $n$ in ROW and $m$ in COL), if both nodes exist the admittance is introduced in $Y$ at position (ROW index, COL index), and it is negative.

The solution of the formulation can be obtained by boolean logic operations [32], or by determinant decision diagrams [23, 40]. Elsewhere, we can formulate a much reduced system of equations in a nullor network, because it also allows us to apply circuit reduction methods $[6,16,21$, 24].

\section{VM and CM nullor-equivalents}

The pathological elements VM and CM are shown in Fig. 1 [2]. These representations are useful in circuit modeling [2, 20, 30, 42], circuit transformation [28, 29, 41], and circuit synthesis $[18,19]$. However, these representations do not allow to include parasitics and they can not be used within the symbolic NA method, because their inverting characteristics do not allow to perform operations as it is done for networks containing nullators and norators [7, 22, 37, 39]. In this manner, we introduce nullor-equivalents for the VM, CM and MO-CM to solve these problems.

\subsection{Nullor-equivalent of the VM}

Among all the possible combinations to generate the nullor-equivalent of the $\mathrm{VM}$, we propose to use the one shown in Fig. 2. In this description $Z_{\text {in }}$ and $Z_{\text {out }}$ are connected in parallel to the input-port and in series to the output-port, respectively, and they model the input and output parasitics. The resistor of value $1 / A_{v}$ is very useful in the NA formulation because the admittance becomes $A_{v}$, and it models the gain or tracking error of the VM. In the ideal case, $Z_{\text {in }}=\infty, Z_{\text {out }}=0$, and $A_{v}=$ unity.

From Fig. 2, $v_{1}=v_{i n}$, and since the voltage across a nullator is zero, $v_{2}=v_{1}=v_{i n}$. Because the current through a nullator is zero, $v_{2}$ generates a loop-current through nodes 2,3 and ground. That way, $i_{a}=\frac{v_{2}}{1 / A_{v}}=A_{v} v_{i n}$ and $i_{b}=i_{a}=A_{v} v_{i n}$. Now $v_{3}=-1 \times i_{b} \quad$ and $\quad v_{4}=v_{3}=$

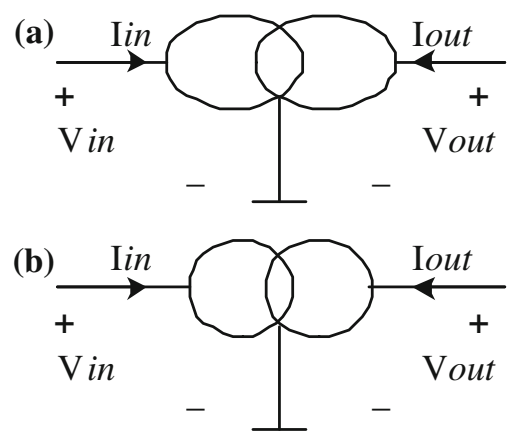

Fig. 1 Representations of a VM and b CM 


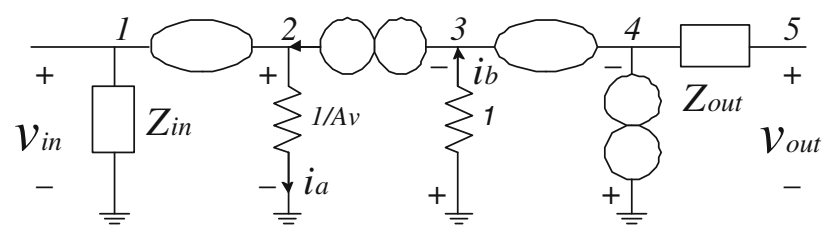

Fig. 2 Nullor-equivalent of the VM including gain, input and output impedances

$-A_{v} v_{i n}$. Finally, we obtain (1). In an ideal VM $v_{\text {out }}=$ $-v_{i n}$

$\left.v_{\text {out }}\right|_{\text {open-circuit }}=-A_{v} v_{\text {in }}$

\subsection{Nullor-equivalent of the $\mathrm{CM}$}

Among all the possible combinations to generate the nullor-equivalent of the $\mathrm{CM}$, we propose to use the one shown in Fig. 3. Indeed, by applying the adjoint network theorem to transform a voltage-mode circuit to a current-mode one $[5,8,10,15,28,29,41]$, this topology is really the adjoint of the VM shown in Fig. 2. In this representation $Z_{\text {in }}$ and $Z_{\text {out }}$ are connected in serie to the input-port and in parallel to the output-port, respectively, and they model the input and output parasitics. Again, the resistor of value $1 / A_{i}$ is very useful in the NA formulation because the admittance becomes $A_{i}$, and it models the gain or tracking error of the CM. In the ideal case, $Z_{\text {in }}=0, Z_{\text {out }}=\infty$, and $A_{i}=$ unity.

From Fig. 3, the nullator connected at node 2 does not allow current to flow, so that a loop-current is formed through nodes $1,2,3$ and ground. In this manner $i_{a}=i_{i n}$, and $v_{3}=1 \times i_{a}=i_{i n}$. The voltage across the nullator is zero so that $v_{4}=v_{3}=i_{i n}$, this generates $i_{b}=\frac{v_{4}}{1 / A_{i}}=A_{i} i_{\text {in }}$. By applying Kirchhoff's current law: $i_{\text {out }}=-\left(i_{b}+i_{\text {Zout }}\right)$. Finally, we obtain (2). In an ideal CM $i_{\text {out }}=-i_{\text {in }}$.

$\left.i_{\text {out }}\right|_{\text {short }- \text { circuit }}=-A_{i} i_{\text {in }}$

\subsection{Nullor-equivalent of the MO-CM}

An extention of Fig. 3, leads us to generate the nullorequivalent of the MO-CM, as shown in Fig. 4. In this representation we are allowed to include independent gain and output impedance for each output $n$.

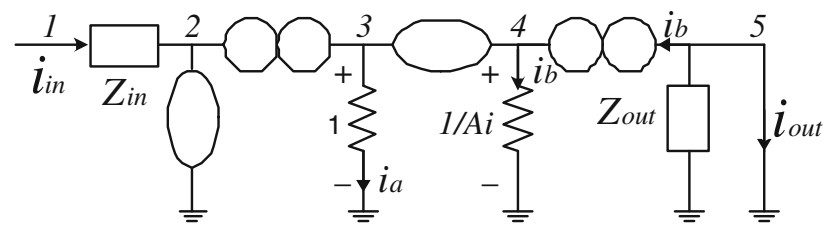

Fig. 3 Nullor-equivalent of the CM including gain, input and output impedances

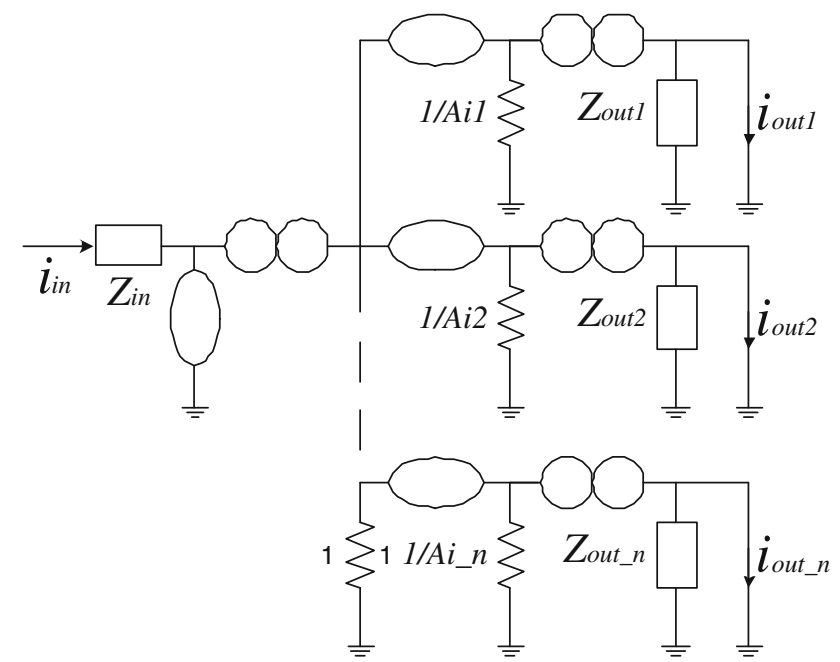

Fig. 4 Nullor-equivalent of the MO-CM including input impedance and independent gain and output impedance for each output $(n)$

\section{Symbolic analysis of analog circuits containing VMs, CMs and/or MO-CMs}

The nullor-equivalents of the VM, CM and MO-CMs can be used directly in symbolic NA of analog circuits, where the output of the VM is not connected to the input of the $\mathrm{CM}$ or MO-CM. Furthermore, when the circuit to be analysed contains a $\mathrm{VM}$ which output is connected to a norator or the input of a CM or MO-CM, we need to apply the superimposing method given in [38], to generate a nullor network containing the same number of nullators and norators, in order to apply the symbolic NA formulation.

Let's us consider the non-inverting and inverting lowpass filter using an inverting positive-type second generation current conveyor (ICCII+) [27]: Its representation using the VM and CM is shown in Fig. 5. As one sees, the output of the VM is connected to the input of the CM. By applying the superimposing method from [38], we obtain the nullor-equivalent network shown in Fig. 6. Basically, the impedance, nullator and norator connected at node 4 in Fig. 2, are superimposed with the impedance, nullator and norator connected at node 2 in Fig. 3. Other nullor-equivalents of inverting and non-inverting current conveyors can be found in [39], which also include parasitic impedances.

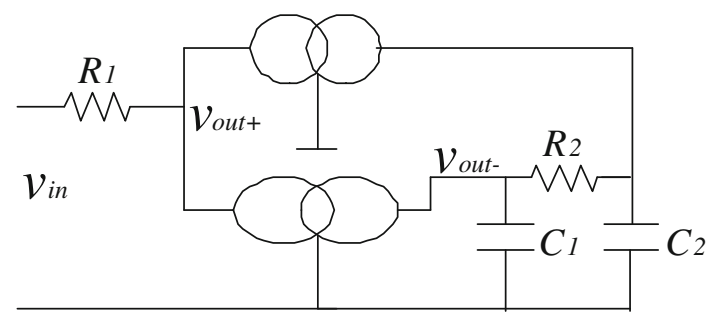

Fig. 5 Non-inverting and inverting low-pass filter taken from [27] 


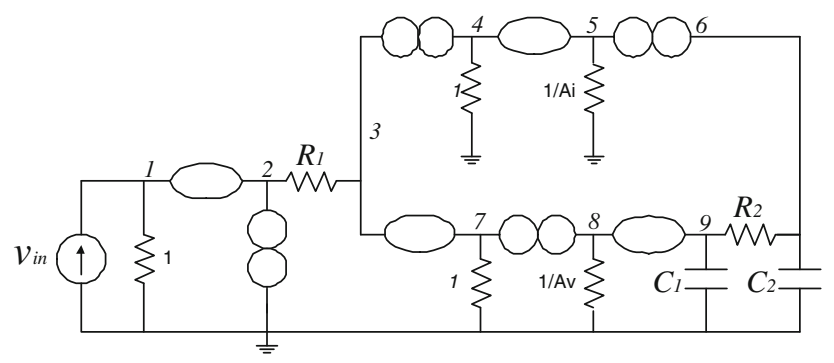

Fig. 6 Nullor-equivalent of Fig. 5

Were we applying the modified nodal analysis (MNA) formulation to Fig. 6, the system of equations becomes order 6, because we need to introduce two stamps: one for the VM with a voltage-controlled voltage source and other for the independent voltage source. On the other hand, by applying the symbolic NA formulation, the order is reduced to 5 , because the independent voltage source has been transformed to a current source [37], and the order becomes to be the number of nodes minus the number of nullator-norator pairs [7]. As a result, for large networks containing many VMs, the symbolic NA formulation is better than by applying the MNA method. For instance, by performing the NA formulation from Fig. 6, the following sets are obtained:

$$
\begin{aligned}
& R O W=\{(1),(3,4),(5,6),(7,8),(9)\} \\
& C O L=\{(1,2),(3,7),(4,5),(6),(8,9)\}
\end{aligned}
$$

The summation of the admittances at each node is presented in Table 1, while the floating admittances are given in Table 2. The NA formulation is given by (3).

$$
\left[\begin{array}{c}
v_{\text {in }} \\
0 \\
0 \\
0 \\
0
\end{array}\right]=\left[\begin{array}{ccccc}
1 & 0 & 0 & 0 & 0 \\
-G_{1} & G_{1} & 1 & 0 & 0 \\
0 & 0 & A_{i} & G_{2}+s C_{2} & -G_{2} \\
0 & 1 & 0 & 0 & A_{v} \\
0 & 0 & 0 & -G_{2} & G_{2}+s C_{1}
\end{array}\right]\left[\begin{array}{c}
v_{1,2} \\
v_{3,7} \\
v_{4,5} \\
v_{6} \\
v_{8,9}
\end{array}\right]
$$

Table 1 Admittances at each node
Table 2 Floating admittances

\begin{tabular}{ll}
\hline Nodes & Admittance \\
\hline$(2,3)$ & G1 \\
$(9,6)$ & G2 \\
\hline
\end{tabular}

The solution of this system taken node 9 as the inverting-output is given by (4). However, in the ideal case $A_{v}=A_{i}=1$, and then (4) is reduced to the symbolic transfer function already provided in (5) [27].

$$
\begin{aligned}
& v_{9}=-\frac{A_{i} v_{i n}}{A_{v} A_{i}+s R_{1} C_{1}+s R_{1} C_{2}+s^{2} R_{1} C_{1} R_{2} C_{2}} \\
& H(s)=-\frac{1}{1+s R_{1}\left(C_{1}+C_{2}\right)+s^{2} R_{1} C_{1} R_{2} C_{2}}
\end{aligned}
$$

From this example, we can conclude on the usefulness of the proposed nullor-equivalents to perform symbolic NA which can be very suitable to enhance the synthesis procedures already introduced in $[4,18,19,34,36]$.

A second example is provided herein by analyzing a universal biquadratic filter using only dual-output CMs and grounded capacitors, it is taken from [33]. Its nullorequivalent is shown in Fig. 7. More complex active filters based on CM arrays can be found in [31].

From the integrated circuit (IC) design point of view, a $\mathrm{CM}$ can provide multiple-outputs (MO-CM), but all of them with the same sign. Besides, when an output with an opposite sign is needed, another CM must be connected, as it is done in this example.

In this manner, the representation in Fig. 7 shows two dual-ouput CMs (DO-CM) labeled by letters $a$ and $c$, they include the input resistance $R_{\text {ina }}$ and $R_{\text {inc }}$, their gains $A_{a 1}$, $A_{a 2}$ and $A_{c 1}, A_{c 2}$, and their output resistances $R_{o a 1}, R_{o a 2}$ and $R_{o c 1}, R_{o c 2}$.

To invert the sign in one output of the DO-CMs, two CMs are also included labeled by letters $b$ and $d$, they include the input resistance $R_{i n b}$ and $R_{\text {ind }}$, their gains $A_{b}, A_{d}$, and their output resistances $R_{o b}, R_{o d}$.

By applying the symbolic NA method, the formulation generates a system of order 9 (19 nodes minus 10 nullors) $[7,22,37]$. The sets for the rows and cols become:

$$
\begin{aligned}
& \text { ROW }=\{(1,11,19),(2,14),(3,6),(4,5),(7,8),(9,10), \\
&(12,13),(15,16),(17,18)\} \\
& \text { COL }=\{(1),(2),(3),(5,6,7),(8),(10,11),(13,14,15), \\
&(16),(18,19)\}
\end{aligned}
$$

The four floating resistances are associated to the inputresistance of the CMs, there are six gains and six outputresistances.

The exact symbolic expression has many symbolic product-of-terms. However, when the output-resistances equal to $\infty$, the reduced symbolic expression is given by 
Fig. 7 Nullor-equivalent of the current-mode filter taken from [33]

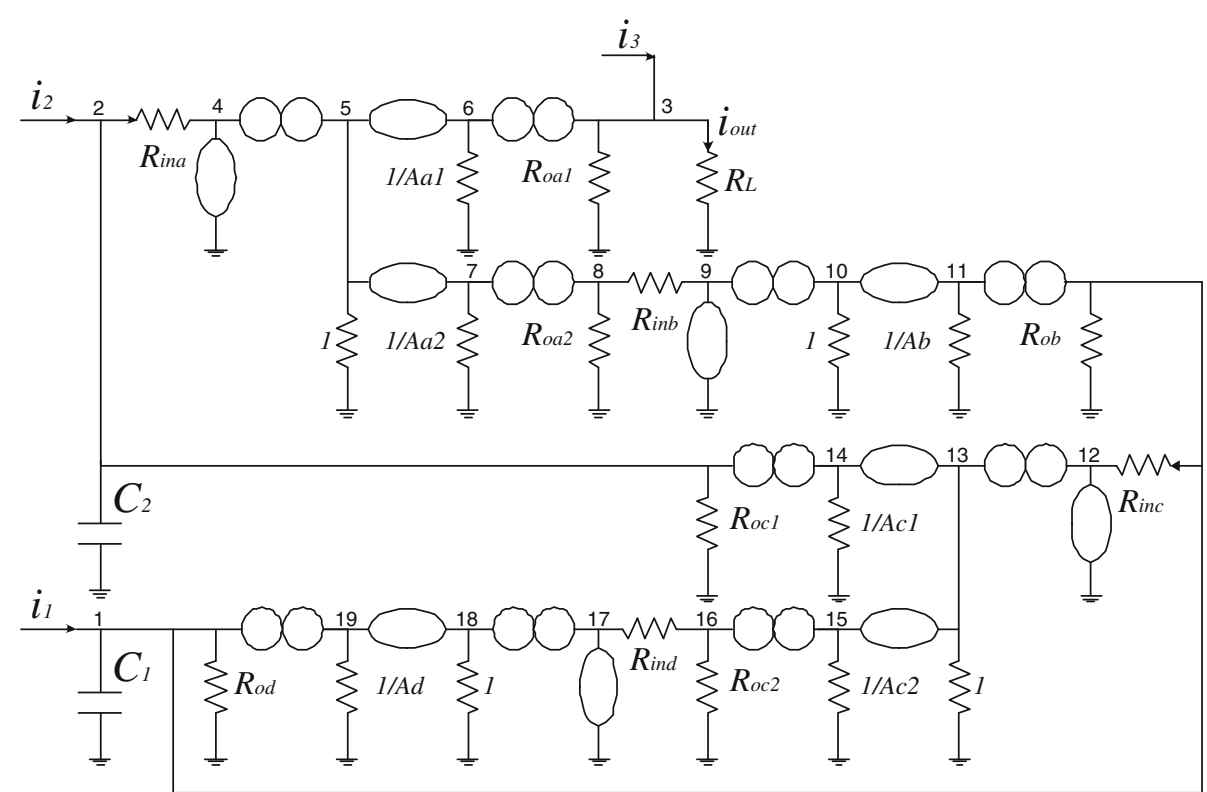

(6). As one sees, only the input resistances $R_{\text {ina }}$ and $R_{\text {inc }}$ are included in the reduced symbolic expression, as already shown in [33]. When the gains are set to unity, (6) becomes (7). are very suitable to perform symbolic NA which can be used within an ADA environment to enhance circuit modeling and synthesis methods, and to validate circuit-equivalents in the transformation of circuit topologies.

$I_{\text {out }}=I_{3}+\frac{-s A_{a 1} I_{2} C_{1} R_{\text {inc }}-A_{a 1} I_{2}+A_{a 1} I_{2} A_{c 2} A_{d}+A_{c 1} A_{a 1} I_{1}}{s^{2} R_{\text {inc }} C_{1} C_{2} R_{\text {ina }}+s\left(C_{1} R_{\text {inc }}+C_{2} R_{\text {ina }}-A_{c 2} A_{d} C_{2} R_{\text {ina }}\right)+A_{c 1} A_{b} A_{a 2}-A_{c 2} A_{d}+1}$

$I_{\text {out }}=I_{3}+\frac{I_{1}-s I_{2} C_{1} R_{\text {inc }}}{s^{2} C_{1} C_{2} R_{\text {ina }} R_{\text {inc }}+s C_{1} R_{\text {inc }}+1}$

\section{Conclusion}

We introduced new nullor-equivalents to represent the pathological elements possessing inverting characteristics, they were the VM and $\mathrm{CM}$, and we introduced also the nullor-equivalent for the MO-CM. These nullor-equivalents were used in the symbolic NA formulation of two active filters. From the results, it can be appreciated that our proposed nullor-equivalents are quite useful to perform symbolic NA to gain insight on the behavior of the circuits, because they include the input and output parasitics and gain. Furthermore, the generated expressions were the same as the ones already provided in the references, but we calculated first the exact symbolic expressions and then we reduced them by approximating ideal characteristics. In this manner, we conclude that our proposed nullor-equivalents
Acknowledgments This work is supported by: UC-MEXUS and CONACyT under grants $\mathrm{CN}-09-310$ and 48396-Y; by PromepMexico under grant UATLX-PTC-088; by Consejeria de Innovacion, Ciencia y Empresa, Junta de Andalucia-Spain TIC-2532; and by the JAE-Doc program of CSIC co-funded by FSE, Spain.

Open Access This article is distributed under the terms of the Creative Commons Attribution Noncommercial License which permits any noncommercial use, distribution, and reproduction in any medium, provided the original author(s) and source are credited.

\section{References}

1. Awad, I. A., \& Soliman, A. M. (1999). Inverting second generation current conveyors: The missing building blocks, CMOS realizations and applications. International Journal of Electronics 86(4), 413-432.

2. Awad, I. A., \& Soliman, A. M. (2002). On the voltage mirrors and the current mirrors. Analog Integrated Circuits and Signal Process 32(1), 79-81.

3. Biolek, D., Senani, R., Biolkova, V., \& Kolka, Z. (2008). Active elements for analog signal processing: Classification, review, and new proposals. Radioengineering 17(4), 15-32. 
4. Cabeza, R., Carlosena, A., \& Serrano, L. (1994). Unified approach to the implementation of universal active devices. Electronics Letters 30(8), 618-620.

5. Carlosena, A., \& Moschytz, G. S. (1993). Nullators and norators in voltage to current-mode transformations. International Journal of Circuit Theory and Applications 21(4), 421-424.

6. Daems, W., Gielen, G., \& Sansen, W. (2002). Circuit simplification for the symbolic analysis of analog integrated circuits. IEEE Transactions on Computer-Aided Design of Integrated Circuits and Systems 21(4), 395-407.

7. Fakhfakh, M., Tlelo-Cuautle, E., \& Fernández, F.V. (2010). Design of analog circuits through symbolic analysis. United Arab Emirates: Bentham Sciences Publishers.

8. Garcia-Ortega, J. M., Tlelo-Cuautle, E., \& Sánchez-López, C. (2007). Design of current-mode gm-c filters from the transformation of opamp-rc filters. Journal of Applied Sciences 7(9), $1321-1326$.

9. Gupta, M., Aggarwal, P., Singh, P. et al. (2009). Low voltage current mirrors with enhanced bandwidth. Analog Integrated Circuits and Signal Process 59(1), 97-103.

10. Herencsar, N., \& Vrba, K. (2007). Current conveyors-based circuits using novel transformation method. IEICE Electronics Express 4(21), 650-656.

11. Kumar P., \& Senani R. (2002). Bibliography on nullors and their applications in circuit analysis, synthesis and design. Analog Integrated Circuits and Signal Process 33(1), 65-76.

12. Kumar, P., \& Senani, R. (2007). Improved grounded-capacitor SRCO using only a single PFTFN. Analog Integrated Circuits and Signal Process 50(2), 147-149.

13. Le, H. B., \& Lee, S. G. (2009). A 1-v low power gain boosted self-cascoding current mirror operational transconductance amplifier. International Journal of Electronics 96(9-10), 10051009.

14. Odess, L., \& Ur, H. (1980). Nullor equivalent networks of nonideal operational-amplifiers and voltage controlled sources. IEEE Transactions on Circuits and Systems 27(3), 231-235.

15. Palomera-Garcia, R. (2005). Generation of equivalent circuits by FTFN relocation. InIEEE ISCAS 1-6, 252-255.

16. Pierzchala, M., \& Rodanski, B. (2001). Generation of sequential symbolic network functions for large-scale networks by circuit reduction two-port. IEEE Transactions on Circuits and Systems I: Fundamental Theory and Applications 48(7), 906-909.

17. Qin, Z., Tan, S. X. D., \& Cheng, C. K. (2005). Symbolic analysis and reduction of VLSI circuits. New York, USA: Springer.

18. Saad, R. A., \& Soliman, A. M. (2008). Generation, modeling, and analysis of CCII-based gyrators using the generalized symbolic framework for linear active circuits. International Journal of Circuit Theory and Applications 36(3), 289-309.

19. Saad, R. A., \& Soliman, A. M. (2008). Use of mirror elements in the active device synthesis by admittance matrix expansion. IEEE Transactions on Circuits and Systems I: Fundamental Theory and Applications 55(9), 2726-2735.

20. Saad, R. A., \& Soliman, A. M. (2010). A new approach for using the pathological mirror elements in the ideal representation of active devices. International Journal of Circuit Theory and Applications. doi:10.1002/cta.534.

21. Sánchez-López, C., \& Tlelo-Cuautle, E. (2008). Novel SBG, SDG and SAG techniques for symbolic analysis of analog integrated circuits. In $S M 2 A C D$, pp. 17-22

22. Sánchez-López, C., \& Tlelo-Cuautle, E. (2009). Behavioral model generation of current-mode analog circuits. In IEEE ISCAS, pp. 2761-2764.
23. Shi, C. J. R., \& Tan, S. X. D. (2000). Canonical symbolic analysis of large analog circuits with determinant decision diagrams. IEEE Transactions on Computer-Aided Design of Integrated Circuits and Systems 19(1), 1-18.

24. Shi, G. Y., Chen, W., \& Shi, C. J. R. (2007). A graph reduction approach analysis. In Proceedings of the Asia South Pacific design automation conference (ASPDAC), pp. 197-202.

25. Sobhy, E. A., \& Soliman, A. M. (2007). Novel CMOS realizations of the inverting second-generation current conveyor and applications. Analog Integrated Circuits and Signal Process 52, $57-64$.

26. Soliman, A. M. (2007). Voltage mode and current mode tow thomas bi-quadratic filters using inverting CCII. International Journal of Circuit Theory and Applications 35(4), 463-467.

27. Soliman A. M. (2008). The inverting second generation current conveyors as universal building blocks. AEU-International Journal of Electronics and Communications 62(2), 114-121.

28. Soliman, A. M. (2009). Adjoint network theorem and floating elements in the NAM. Journal of Circuits Systems and Computers 18(3), 597-616.

29. Soliman, A. M. (2009). On the DVCC and the BOCCII as adjoint elements. Journal of Circuits Systems and Computers 18(6), 1017-1032.

30. Soliman, A. M. \& Saad, R.A. (2010). The voltage mirror-current mirror pair as a universal element. International Journal of Circuit Theory and Applications. doi:10.1002/cta.596.

31. Souliotis, G., \& Haritantis, I. (2008). Current-mode filters based on current mirror arrays. International Journal of Circuit Theory and Applications 36(2), 173-183.

32. Tan, S. X. D. (2006). Symbolic analysis of analog circuits by boolean logic operations. IEEE Transactions on Circuits and Systems II: Analog and Digital Signal Processing 53(11), 1313 1317.

33. Tangsrirat, W., \& Prasertsom, D. (2007). Electronically tunable low-component-count current-mode biquadratic filter using dualoutput current followers. Electrical Engineering 90, 33-37.

34. Tlelo-Cuautle, E., \& Duarte-Villaseñor, M. A. (2008). Evolutionary electronics: Automatic synthesis of analog circuits by GAs chap. In Success in evolutionary computation series: Studies in computational intelligence. Springer, Berlin, pp. 165-188.

35. Tlelo-Cuautle, E., Duarte-Villaseñor, M. A., \& Guerra-Gómez, I. (2008). Automatic synthesis of VFs and VMs by applying genetic algorithms. Circuits, Systems and Signal Processing 27(3), 391403.

36. Tlelo-Cuautle, E., Guerra-Gómez, I, Reyes-Garcia, C. A., \& Duarte-Villaseñor, M. A. (2010). Synthesis of analog circuits by genetic algorithms and their optimization by particle swarm optimization chap. In Intelligent systems for automated learning and adaptation: Emerging trends and applications. Information Science Reference: IGI Global, pp. 173-192.

37. Tlelo-Cuautle, E., Martinez-Romero, E., Sánchez-López, C., \& Tan, S.X.D. (2009). Symbolic formulation method for mixedmode analog circuits using nullors. In IEEE ICECS.

38. Tlelo-Cuautle, E., Moro-Frias, D., Sánchez-López, C., \& DuarteVillaseñor, M. A. (2008). Synthesis of CCII-s by superimposing VFs and CFs through genetic operations. IEICE Electronics Express 5(11), 411-417.

39. Tlelo-Cuautle E., Sánchez-López C., \& Moro-Frias D. (2010). Symbolic analysis of (MO)(I)CCI(II)(III)-based analog circuits. International Journal of Circuit Theory and Applications. doi: $10.1002 /$ cta.582.

40. Verhaegen, W., \& Gielen, G. (2002). Efficient DDD-based symbolic analysis of linear analog circuits. IEEE Transactions on 
Circuits and Systems II: Analog and Digital Signal Processing 49(7), 474-487.

41. Wang, H. Y., Chang, S. H., Jeang, Y. L. et al. (2006). Rearrangement of mirror elements. Analog Integrated Circuits and Signal Process 49(1), 87-90.

42. Wang, H. Y., Lee, C. T., \& Huang, C. Y. (2005). Characteristic investigation of new pathological. Analog Integrated Circuits and Signal Process 44(1), 95-102.

43. Zito D. (2009). A novel low-power receiver topology for $\mathrm{rf}$ and microwave applications. International Journal of Circuit Theory and Applications 37(9), 1008-1018.

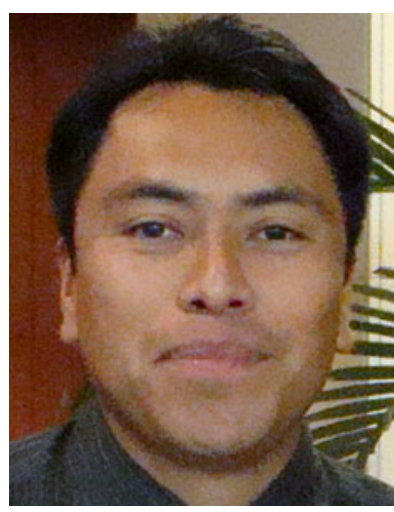

E. Tlelo-Cuautle received the B.Sc. degree from the Instituto Tecnológico de Puebla (ITP), Mexico, in 1993, and the M.Sc. and $\mathrm{Ph} . \mathrm{D}$. degrees from the Instituto Nacional de Astrofisica, Optica y Electrónica (INAOE), Mexico, in 1995 and 2000, respectively. In 1995 he joined the ITP and since 2001 he has been a full researcher at INAOE. He has coauthored two books, six book chapters and more than 120 papers on scientific journals and conference proceedings. He is IEEE senior member and IEICE member. He serves in the editorial board of the Journal of Applied Sciences, and is reviewer in 16 journals, among them: IEEE Trans on ComputerAided Design; IEEE Trans on Circuits and Systems; IET Circuits, Devices \& Systems; Int Journal of Electronics; Rev Mexicana de Fisica; IET Electronics Letters; Circuits, Systems and Signal Processing; IEEE Latin-America Transactions. He has been a member of the Program Committee in MDES 2009-2010; IEEE ICECS 2009; WCECS 2007-2009; IEEE and ACM CSTST 2008; and IASTED Circuits, Signals and Systems 2003-2005. He has been reviewer in 15 international conferences, among them: IEEE CERMA, IEEE APCCAS, IEEE ISCAS, IEEE ECCTD and IEEE ANDESCON. His research interests include modeling and simulation of linear and nonlinear circuits and systems, symbolic analysis, circuit synthesis, and analog/RF and mixed-signal CAD tools.

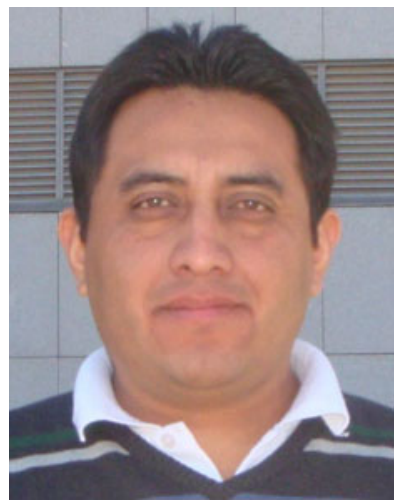

C. Sánchez-López received the B.Sc. degree in electronics engineering from the Benemerita Universidad Autonoma de Puebla (BUAP), Mexico, in 1999, and the M.Sc. and Ph.D. degrees from the Instituto Nacional de Astrofisica, Optica y Electronica (INAOE), Mexico, in 2002 and 2006, respectively. In 2006 he joined Universidad Autonoma de Tlaxcala (UAT), Mexico as full professor and researcher. From June 2009 he is a Postdoctoral Research Fellow at the Instituto de Microelectronica de Sevilla (IMSE-CSIC),
Spain. He is the author of more than 50 research journal papers and international proceedings published in the fields of modeling and simulation of linear and nonlinear circuits and systems, symbolic analysis, mixed-signal circuits, RF-circuits and computer-aided circuit design.

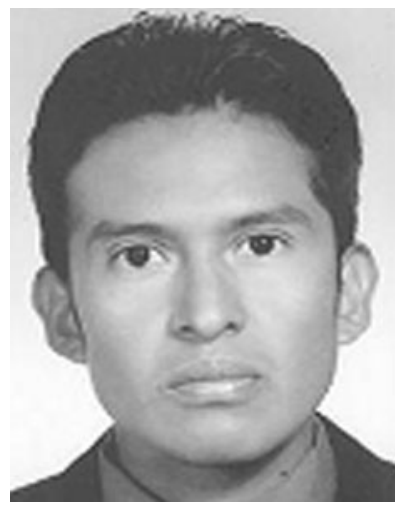

E. Martinez-Romero received the B.Sc. degree from the Autonomus University of Puebla (BUAP), Mexico, in 2006. $\mathrm{He}$ is currently M.Sc. student at National Institute of Astrophysics, Optics and Electronics (INAOE), Mexico. His research interests include Model Order Reduction, symbolic analysis techniques and analog circuit design.

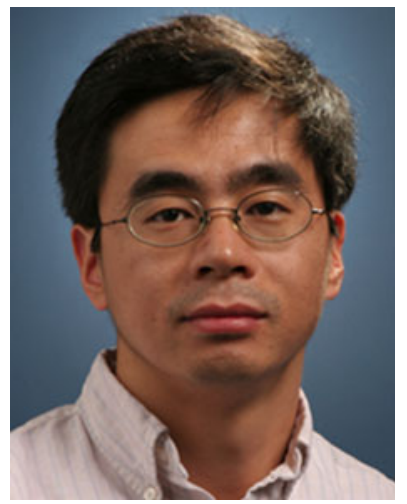

Sheldon X.-D. Tan received his B.Sc. and M.Sc. degrees in electrical engineering from Fudan University, Shanghai, China in 1992 and 1995, respectively and the Ph.D. degree in electrical and computer engineering from the University of Iowa, Iowa City, in 1999. He is an Associate Professor in the Department of Electrical Engineering, University of California, Riverside. He was a faculty member in the Electrical Engineering Department of Fudan University from 1995 to 1996. His research interests include modeling and simulation of analog/RF/mixed-signal and interconnect circuits, analysis and optimization of high performance power and clock distribution networks, architecture level thermal, power, modeling and simulation for multicore microprocessors and embedded system designs based on FPGA platforms. He also coauthored books "Symbolic Analysis and Reduction of VLSI Circuits" by Springer/Kluwer 2005 and "Advanced Model Order Reduction Techniques for VLSI Designs”, by Cambridge University Press 2007. Dr. Tan now is serving as an Associate Editor for three journals: ACM Transaction on Design Automation of Electronic Systems (TODAE), Integration, The VLSI Journal, and Journal of VLSI Design. He received Outstanding Overseas Investigator Collaboration Award from the National Natural Science Foundation of China (NSFC) in 2008. He received NSF CAREER Award in 2004. Dr. Tan received the Best Paper Award from 2007 IEEE International Conference on Computer Design (ICCD’07), a Best Paper Award Nomination from 2005 and 2009 IEEE/ACM Design Automation Conference, the Best Paper Award from 1999 IEEE/ACM Design Automation Conference. He served as a technical program committee member for ASPDAC, BMAS, ASPDAC, ISQED, ICCAD. 